\title{
Ionic liquid as Functional Dispersant for Nanomaterials in Polymer Matrix
}

\author{
Jiji Abraham*, Hanna J Mariya and Sabu Thomas \\ International and Inter University Centre for Nanoscience and Nanotechnology, India
}

Submission: July 30, 2018; Published: October 09, 2018

*Corresponding author: Jiji Abraham, International and Inter University Centre for Nanoscience and Nanotechnology, Mahatma Gandhi University, India, Email: jijiabraham02@gmail.com

Abstract

Ionic liquid has been used as a novel dispersant for fillers in polymer matrix. Enhanced interfacial interaction between reinforcing material and polymer matrix leads to smart materials. Use of ionic liquid as a modifier is environmentally friendly method to fabricate nanocomposites potential applications.

Keywords: Ionic liquid; Polymer matrix; Interfacial interaction; Potential applications

Abbreviations: RTILs: Room-Temperature Ionic Liquids; MWCNT: Multiwalled Carbon Nanotube; GO: Graphene Oxide; BNNS: Boron Nitride Nanosheets; BIIR: Bromo butyl Rubber; ILs: Ionic Liquids; GO-ILs: Modified Graphene Oxide; MEMS/NEMS: Micro/Nanoelectromechanical Systems; ZIL: Zwitterionic Imidazolium-Based Ionic Liquid

\section{Ionic liquid as a Functional Dispersant for Nano- materials in Polymer matrix}

Potential applications as well as strength and durability of polymers can be enriched by the reinforcement using various nanosized fillers. However wide spread application of nanomaterials as reinforcing agents has limited due to their processing difficulty and the tendency to form agglomerates. Incorporation of active groups on fillers by emerging chemistry is a good method to overcome the problems associated with filler dispersion. At present, many advanced strategies have been developed to improve the dispersibility and stability of nanofillers in solvents and matrices which include (a) the covalent attachment of functional groups through chemical reactions (b) the non-covalent adsorption or wrapping of various functional molecules. Due to some structural alteration and the need of additional solvent during covalent fictionalisation, non-covalent functionalization is preferred.

Non-covalent functionalization of fillers by Room-Temperature Ionic Liquids (RTILs) has got considerable attention in these days. RTILs, usually liquid at or near room temperature are nonvolatile, non-flammable and thermally stable. They provide an environmentally benign "green" alternative to organic solvents for chemical synthesis, extractions and bio catalysis [1].

Use of ionic liquid as novel dispersant for fillers has been developed as an environment friendly technology to functionalize them. Commonly reported dispersants are solid in state which needs additional solvent to disperse nanomaterial. In contrast ionic liquids are fluid at room temperature and are made entirely of ions (asymmetric cation and a symmetric anion) [2].

Das et al. first reported the use of ionic liquid as a dispersing agent for Multiwalled Carbon Nanotube (MWCNT) [3]. Cation- $\pi$ interaction between cationic part of ionic liquid and $\pi$ conjugated MWCNT surface is the reason behind the dispersion of MWCNT. Since ionic liquid can act a dispersant, it will improve overall performance of the nanocomposites. Researches from the same group had tried different ionic liquids to functionalize MWCNT and studied its effect on various properties of fabricated nanocomposites. These studies showed a clear evidence for the enhanced dispersion of MWCNT in presence of ionic liquid, improved cure characteristics, mechanical performance, dielectric characteristics, electrical conductivity, ionic conductivity, thermal stability, thermal conductivity oxidation resistance, thermo mechanical properties and processability. Flexible and stable electromagnetic shielding materials can be fabricated with the aid of ionic liquid modified MWCNT $[4,5]$.

Studies also reported in the area of dispersing other fillers like graphene, graphite oxide, graphene oxide, clay, layered double hydroxides, silica, carbon black etc. with the aid of ionic liquid. On mixing Graphene Oxide (GO) and ionic liquid, ILs had been effectively intercalated into the interlayer of GO, which was found to be able to raise the exfoliation degree of GO. It is found that both thermal stability and the thermal conductivity of Bromobutyl Rubber(BIIR)nanocomposites could be improved byincorporating 
the Ionic Liquids (ILs) modified graphene oxide (GO-ILs) [6]. Tribological study of functionalized graphene-IL nanocomposite ultrathin lubrication films on $\mathrm{Si}$ substrates the promising applications in the lubrication of micro/nanoelectromechanical systems (MEMS/NEMS) [7]. It is possible to control the pore size, electrical conductivity and mechanical robustness of the polyurethane nanocomposite foam by incorporating it with modified the graphene oxide using 1-methyl imidazole chloride ionic liquid [8]. Boron Nitride Nanosheets (BNNS) are exfoliated with the help of ionic liquid by physical adsorption on IL on BNNS surfaces. Highly thermally conductive and electrically insulating polymer nanocomposites can be prepares using this material [9].

Ionic liquid can be used as interfacial agent or surfactant or organic modifier for layered double hydroxide in polymer nanocomposites [10]. Ionic liquids were used as an environmentally friendly material to improve the processability of layered silicates containing polymer nanocomposites [11]. Zwitterionic Imidazolium-Based Ionic Liquid (ZIL) was used to modify both cationic and anionic clay minerals. The ZIL was able to penetrate into the interlayer space of clay and modified the interfacial properties [12]. Studies have been reported on the role of ionic liquid as an interfacial modifier for silica and as a cure accelerator in polymer nanocomposites [13].

In conclusion the use of ILs afforded not only high-yield, mild, facile exfoliation of various fillers but also non-covalent functionalization of fillers for multifunctional applications. Merging processing techniques of nanocomposites with ionic liquid for efficient dispersion of nanomaterials facilitates the development of new, high performance materials.

\section{References}

1. (2011) Chemical reviews 111(5): 3508-35076.
2. Buzzeo MC, Evans RG, Compton RG (2004) Non-Haloaluminate Room-Temperature Ionic Liquids in Electrochemistry-A Review. ChemPhysChem 5(8): 1106-1120.

3. (2009) Carbon 47(14): 3313-3321.

4. Sharma M, Sharma S, Abraham J, Thomas S, Madras S, et al. (2014) Flexible EMI shielding materials derived by melt blending PVDF and ionic liquid modified MWNTs. Materials Research Express 1(3): 035003.

5. Abraham J, ArifPM,Xavier P, Bose S, George SC, etal. (2017) Investigation into dielectric behaviour and electromagnetic interference shielding effectiveness of conducting styrene butadiene rubber composites containing ionic liquid modified MWCNT. Polymer 112: 102-115.

6. Xiong X, Wang J, Jia H, Fang E, Ding L (2013) Structure, thermal conductivity, and thermal stability of bromobutyl rubber nanocomposites with ionic liquid modified graphene oxide. Polymer degradation and stability 98(11): 2208-2214.

7. (2011) The Journal of Physical Chemistry C 115(27): 13275-13284.

8. Titash Mondal, Suman Basak, Anil K B (2017) Ionic liquid modification of graphene oxide and its role towards controlling the porosity, and mechanical robustness of polyurethane foam. Polymer 127: 106-118.

9. Takuya Morishita, Naoko Takahashi (2017) Highly thermally conductive and electrically insulating polymer nanocomposites with boron nitride nanosheet/ionic liquid complexes. RSC Advances 7(58): 36450-36459.

10. Lins LC, Bugatti V, Livi S, Gorrasi G (2018) Phosphonium ionic liquid as interfacial agent of layered double hydroxide: Application to a pectin matrix Carbohydrate polymers 182: 142-148.

11. Livi S, Jannick Duchet-Rumeau, Jean-François Gérard (2012) Application of supercritical $\mathrm{CO} 2$ and ionic liquids for the preparation of fluorinated nanocomposites. Journal of colloid and interface science 369(1): 111-116.

12. Bluma G, Soares, Stephane C, Ferreira, Livi S (2017) Modification of anionic and cationic clays by zwitterionic imidazolium ionic liquid and their effect on the epoxy-based nanocomposites. Applied Clay Science135: 347-354.

13. (2017) Journal of Applied Polymer Science 134(7).

\section{Your next submission with Juniper Publishers} will reach you the below assets

- Quality Editorial service

- Swift Peer Review

- Reprints availability

- E-prints Service

- Manuscript Podcast for convenient understanding

- Global attainment for your research

- Manuscript accessibility in different formats

( Pdf, E-pub, Full Text, Audio)

- Unceasing customer service

Track the below URL for one-step submission

https://juniperpublishers.com/online-submission.php 